\title{
Algumas pistas (e armadilhas) na utilização da Etnografia na Educação
}

\author{
Amurabi Oliveira ${ }^{1}$ \\ amurabi_cs@hotmail.com
}

\section{Resumo}

Este trabalho visa trazer uma reflexão em torno da utilização da Etnografia na pesquisa educacional. De forma mais específica, busca apontar para algumas pistas na sua utilização, indicando também algumas armadilhas postas. Nossa reflexão parte do pressuposto de que há uma indissociabilidade entre teoria e método, de modo que não podemos reduzir a Etnografia a uma simples técnica de "coleta de dados", o que seria deturpação. Nesse sentido, pensar a Etnografia no campo da educação é também pensar a produção do conhecimento antropológico na educação. A partir dessa perspectiva, refutamos algumas posições amplamente difundidas no âmbito da pesquisa educacional que afirmam que não há pesquisas etnográficas em educação, mas apenas pesquisas do "tipo etnográfico", o que em nossa leitura se origina de uma leitura reducionista e extremamente superficial da Etnografia, ou mesmo inexistente, da antropologia.

Palavras-Chave: Etnografia; Antropologia da Educação; pesquisa educacional.

1 Doutor em Sociologia pela Universidade Federal de Pernambuco (UFPE). Professor da Universidade Federal de Alagoas (UFAL). 


\title{
Some clues (and traps) in the use of Ethnography in Education
}

\begin{abstract}
This work aims to bring a reflection on the use of ethnography in educational research, more specific search point to some clues in their use, indicating also put some traps. Our reflection assumes that there is an inseparability of theory and method, so that we can not reduce ethnography to a simple technique of "collecting data", which would be misrepresentation, in this sense, thinking ethnography in education is also think the production of anthropological knowledge in education. From this perspective refute some positions widely disseminated within the educational research claiming that there is ethnographic research in education, but only searches "ethnographic", which in our reading stems from a reductionist reading of ethnography, and extremely superficial, or even nonexistent, anthropology.
\end{abstract}

Keywords: Ethnography; Anthropology of Education; educational research.

\section{Introdução}

Muito tem se aventado sobre os procedimentos metodológicos na pesquisa educacional, que, no Brasil, se estrutura principalmente, mas não unicamente, a partir da realidade acadêmica, em especial em nível de pós-graduação, cuja tradição tem prosseguido "[...] focalizando os problemas da educação segundo suas orientações teóricas e ideológicas, utilizando em menor ou maior grau, conforme os perfis de cada grupo, dados empíricos colhidos em pequena escala, geralmente de cunho qualitativo." (CAMPOS, 2009, p. 271-272). Inegavelmente, no Brasil, as pesquisas têm se desenvolvido principalmente a partir da abordagem qualitativa. Isso se deu a partir dos anos 1970 do século passado, consolidando-se na década seguinte, como nos apontam Gatti e André (2011). Isso não implicou uma reflexão epistemológica mais profunda sobre o universo das pesquisas qualitativas, que é bastante amplo 
(CHIZZOTTI, 2003), de modo que:

As alternativas apresentadas pelas análises chamadas qualitativas compõem um universo heterogêneo de métodos e técnicas, que vão desde a análise de conteúdo com toda sua diversidade de propostas, passando pelos estudos de caso, pesquisa participante, estudos etnográficos, antropológicos etc. (GATTI, 2001, p. 73)

Além do mais, há de se reconhecer que, por mais que as abordagens qualitativas na pesquisa em Educação tenham ganhado grande visibilidade, ainda são alvo de questionamento por parte de alguns pesquisadores, sobretudo acerca da representatividade, da subjetividade, bem como dos problemas técnicos relacionados à coleta, ao processamento e à análise dos dados (MARTINS, 2004).

Nessa ampla seara das metodologias qualitativas, a Etnografia tem se destacado no universo da pesquisa educacional, como nos apontam os balanços realizados por Garcia (2001) e Lima (2001). Também André (1997, p. 46) ressalta que:

No final dos anos 70, os pesquisadores educacionais mostram grande interesse pela etnografia, especialmente motivados pelo estudo das questões de sala de aula e pela avaliação curricular. Esse movimento de aproximação vai, pouco a pouco, se adensando, e com a produção crescente de trabalhos ficam cada vez mais evidentes os ganhos, mas também os problemas e as futuras direções.

Buscamos dar relevo à contribuição da Etnografia na pesquisa educacional, indicando algumas "pistas" em torno de sua utilização. Também nos preocupamos em criticar uma perspectiva amplamente divulgada de que não há estudos etnográficos em Educação, mas sim estudos do tipo etnográfico (ANDRÉ, 1995), esses serão nossos eixos principais ao longo deste breve trabalho.

O que apresentamos aqui é uma síntese de algumas discussões metodológicas que vêm sendo desenvolvidas dentro do grupo de pesquisa Educação \& Ciências Sociais, que congrega uma série de investigações etnográficas desenvolvida no espaço escolar, tanto por educadores, quanto por cientistas sociais. Nosso objetivo maior com este artigo é contribuir para a reflexão em torno da utilização da Etnografia na pesquisa educacional, considerando a bibliografia pertinente ao 
campo da Antropologia. Apesar de haver uma série de autores que tem se proposto a desenvolver esse tipo de reflexão, fica evidente que ainda há uma utilização superficial da Etnografia, corriqueiramente apropriada de forma reducionista, e como bem nos indicam Tosta, Moreira e Bueniconto (2008), ao analisarem as teses e dissertações em Educação que se afirmam etnográficas, não há por parte dos autores desses trabalhos um entendimento em torno dos princípios básicos dessa metodologia.

\section{Antropologia, Etnografias e Educação: diálogos possíveis}

Para compreendermos melhor as questões aqui postas, devemos considerar primeiramente o diálogo estabelecido entre a Antropologia e a Educação. Entendemos que não se desvincular teoria e método, de modo que reduzir a Etnografia a uma "técnica de coleta de dados", sem compreender a relação dela com os conceitos da antropologia implicaria equívoco (VALENTE, 1996). Também Alves-Mazotti (2001) chama atenção para a pobreza teórico-metodológica de muitas pesquisas educacionais, que, em grande medida, dão pouca atenção ao conhecimento acumulado na área, não permitindo uma análise mais consistente dos referenciais conceituais disponíveis para a abordagem do tema de interesse do pesquisador.

Notoriamente o diálogo entre a Antropologia e a Educação não é algo recente (GUSMÃO, 1997). Podemos citar uma longa tradição que se instaura no campo dos estudos da infância que acompanham a ciência antropológica desde a sua gênese (ROCHA; TOSTA, 2009), que acabou por se debruçar sobre os processos de educação não escolares. De forma mais pontual, no Brasil, temos uma tradição muitas vezes esquecida pelos antropólogos que remete aos laboratórios de Antropologia Pedagógica ainda no começo do século XX, que funcionavam junto às Escolas Normais, voltadas para a formação de professores (OLIVEIRA A., 2012; 2013a). Ao analisar o atual contexto, Dauster (2007, p. 31-32) indica que a contribuição da Antropologia para a Educação se daria da seguinte maneira:

Do meu ponto de vista, ao considerar a entrada da Antropologia no campo da Educação, não busco transformar o profissional da educação em antropólogo na sua atividade docente, ou de 
pesquisador e autor de uma tese ou dissertação. Fica, contudo, posto o desafio de partilhar com esse profissional a apreensão de outras relações e posturas no exercício de leituras dos fenômenos tidos como de socialização ou de Educação. Na pesquisa, em todos os sentidos, abre-se, assim, o horizonte da construção do objeto segundo uma outra ótica e a partir de outras atitudes e formas de problematizar apropriadas do campo antropológico e de sua prática, a saber, a observação participante.

A discussão em torno do conceito antropológico da cultura é gerada de transformações do olhar, pois instiga o abandono de estereótipos, conduz à desnaturalização de fenômenos, na medida em que eles passam a ser vistos como histórica e socialmente construídos, além de observados nas suas possíveis diferenças culturais. Isto não impede, entretanto, que sejam observadas as similitudes simbólicas entre os mesmos. As limitações das visões etnocêntricas são descobertas em confronto com o "olhar" relativizador e a busca do ponto de vista do universo social nos seus termos.

Em consonância com o que foi afirmado pela autora, chamamos atenção para a necessidade da produção de um conhecimento antropológico no âmbito da Educação, apenas dessa maneira é que podemos vislumbrar uma efetiva contribuição de um campo para outro, bem como só a partir da produção do conhecimento é que há um diálogo real entre essas duas áreas. Nesse sentido, devemos reconhecer que "[...] a interlocução da Antropologia no campo da docência em Educação e nos cursos de Pedagogia desafia o conhecimento e a própria prática antropológica." (GUSMÃO, 2006, p. 300). Isso seria possível mediante o desenvolvimento da pesquisa etnográfica no campo da Educação, afinal, é por meio da Etnografia que a própria teoria antropológica se renova (PEIRANO, 1995).

Segundo Sirota (1994), a análise do cotidiano escolar na sala de aula por meio da Etnografia, a partir dos anos 1950 do século XX, trouxe grande renovação acadêmica com relação às pesquisas que vinham se desenvolvendo até então. Ainda segundo a autora:

[...] essa abordagem da sala de aula se opõe tanto à concepção implícita (que Delamont qualifica de pesquisa empírica sem alma) de um certo número de psicólogos que trabalham na área educativa, e que pressupõe que os seres humanos são feitos para aprender mais, melhor e mais depressa (Max e Wax), 
quanto às concepções de alguns pesquisadores e etnólogos que não identificam os alunos senão em termos de características sociais, étnicas ou religiosas, considerando-os como átomos sociais $(\mathrm{Ogbu})$. Deste modo, essas pesquisas têm em comum o fato de centrar-se na interação face a face a fim de descrever e compreender a organização social da sala de aula, bem como na relação adulto-criança no interior e no exterior do quadro escolar, a partir das perspectivas dos atores. Além disso, elas consideram a sala de aula como um microcosmo da sociedade global na qual a escola está situada e onde as características da sociedade são recriadas na interação cotidiana.

A utilização da etnografia como ciência da descrição cultural coloca então o pesquisador em condições de observar os comportamentos em seu quadro natural e de obter das pessoas observadas as estruturas de significação que tornam compreensível a trama de um comportamento. A prática da etnografia permite assim descobrir o saber cultural possuído pelos indivíduos enquanto indígenas, assim como os meios através dos quais esse saber cultural é utilizado na interação social. (p. 29).

Devemos ter em vista que a Educação se renova por meio de um intenso diálogo com as diversas ciências, de modo que a ciência antropológica traz novo olhar para a realidade educacional até então ausente, ou pelo menos pouco visível; afinal, uma das características da Antropologia é se dedicar a temas que aparentemente seriam sem importância para outros pesquisadores, relacionando-os a outras questões, muitas vezes encaradas como de extrema importância por esses mesmos pesquisadores.

Juntamente com a Antropologia, o Interacionismo Simbólico e a Etnometodologia trouxeram avanços consideráveis para as pesquisas em Educação, também lançando um olhar para o cotidiano e para os processos interacionais, ainda que a partir de um outro substrato teórico, bem como a partir de uma outra leitura da relação que se estabelece entre agência e estrutura, sendo que tais correntes são muitas vezes acusadas de privilegiar em demasia a dimensão da agência em detrimento da estrutura (COULON, 1995).

Tendo em vista tais considerações, buscaremos neste breve artigo apontar alguns caminhos possíveis, indicando também algumas 
armadilhas recorrentes para a utilização da Etnografia no campo educacional a partir de uma revisão bibliográfica. Dessa forma, assumimos como pressuposto a ideia de que a Etnografia não pode ser resumida a uma "técnica de coleta de dados", devendo ser compreendida na íntima relação entre teoria e método e no processo de produção do conhecimento antropológico em Educação.

\section{Etnografando a realidade escolar: pistas e armadilhas}

Como já apontamos anteriormente, houve uma profusão dos métodos qualitativos no campo educacional, o que implicou também a difusão da Etnografia nessas pesquisas. Obviamente que o processo de apropriação de um campo por outro não se dá sem tensões e sobressaltos; entretanto, antes de entrarmos no mérito da questão, preocuparemo-nos em esclarecer um pouco sobre a própria Etnografia, seus pressupostos e suas possibilidades abertas.

Em termos históricos, a Etnografia se torna visível a partir da publicação de Os Argonautas do Pacífico Ocidental (1976), em 1922, por Malinowski. Ainda que outros antropólogos tenham realizado trabalho de campo anteriormente, coube ao antropólogo polaco sistematizar a utilização desse método, afirmando como pressuposto o contato prolongado com o "nativo", por meio de longas permanências em campo e por meio de uma verdadeira imersão na cultura do outro. Obviamente que seguir os pressupostos abertos por Malinowski no processo de pesquisa com culturas estrangeiras, por assim dizer, é mais simples do que quando se trata da própria cultura do pesquisador, realidade esta com a qual se defrontam os pesquisadores do campo da Educação. Isso porque, via de regra, deparam-se com uma realidade social e cultural com a qual já estão familiarizados, mais que isso, da qual fazem parte. Porém, certamente, essa não é razão suficiente para se afirmar que há uma impossibilidade na realização da Etnografia na pesquisa educacional, uma vez que há toda uma longa tradição no próprio campo da Antropologia em que isso é realizado, o que se acelerou na segunda metade do século XX. 
Nesse sentido, são elucidativas as questões trazidas por Eckert e Rocha (2003, p. 3), ao problematizarem a produção de uma Etnografia de rua, portanto, em um contexto substancialmente diferente daquele no qual Malinowski forjou os fundamentos da pesquisa etnográfica. Segundo as autoras:

A etnografia consiste em descrever práticas e saberes de sujeitos e grupos sociais a partir de técnicas como observação e conversações, desenvolvidas no contexto de uma pesquisa. Interagindo-se com o Outro, olha-se, isto é, "ordena-se o visível, organiza-se a experiência" conforme propõe Régis Debray. O etnógrafo descreve, tradicionalmente em diários, relatos ou notas de campo, seus pensamentos ao agir no tempo e espaço histórico do Outro-observado, delineando as formas que revestem a vida coletiva no meio urbano. A etnografia de rua, aqui, é um deslocamento em sua própria cidade, o que significa dizer, dentro de uma proposta benjaminiana, que ela afirma uma preocupação com a pesquisa antropológica a partir do paradigma estético na interpretação das figurações da vida social na cidade. Um investimento que contempla uma reciprocidade cognitiva como uma das fontes de investigação, a própria retórica analítica do pesquisador em seu diálogo com o seu objeto de pesquisa, a cidade e seus habitantes. Uma vez que tal retórica é portadora de tensões entre uma tradição de pensamento científico e as representações coletivas próprias que a cidade coloca em cena, o pesquisador constrói o seu conhecimento da vida urbana na e pela imagem que ele com-partilha, ou não, com os indivíduos e/ou grupos sociais por ele investigados.

Percebamos, portanto, que afirmar simplesmente que não se realiza Etnografia em Educação, mas apenas pesquisas do "tipo etnográfico" (ANDRÉ, 1995) - argumento que, no caso da Educação, há uma adaptação da Etnografia, ao menos se compreendemos a Etnografia no seu modelo "clássico" -, implica um reducionismo simplista, por não compreender a própria dinâmica e as transformações da Antropologia, e da Etnografia, nas últimas décadas. Os nativos não são mais os mesmos, e a Etnografia também não.

Esse método, aqui afirmamos, pressupõe a possibilidade de um duplo movimento: de irmos até os agentes sociais, e de trazermos esses agentes em sua totalidade até nós, por meio da descrição etnográfica, ou nos dizeres de Geertz (2005, p. 188): “estar lá e estar aqui”. Nesse 
processo, devemos reconhecer "[...] o fato incontornável de que todas as descrições etnográficas são de fabricação caseira, são as descrições de quem descreve, e não as daqueles ou daquilo que é descrito.", pois, como o próprio autor já indicou em textos anteriores (GEERTZ, 1989), a Etnografia busca captar o sentido que os sujeitos atribuem a suas ações; contudo, o que realizamos é uma interpretação sobre a interpretação do agir do "nativo", de modo que realizamos uma interpretação de segunda mão.

Ao nos depararmos com uma realidade com a qual estamos familiarizados, no caso o universo escolar, algumas questões parecem ser minimizadas em termos de interpretação; todavia, não nos enganemos, pois nem tudo que nos é familiar é realmente conhecido. Se por um lado a etnografia busca trazer esses agentes "reais" para o nosso campo de pesquisa, proporcionando uma aproximação entre pesquisador e pesquisado, entre o pesquisador e o cotidiano daqueles que ele observa e investiga, por outro, a etnografia deve ser pensada como processo de estranhamento da realidade, de desnaturalização desta. Poderíamos reduzir a contribuição mais substancial da Etnografia para o campo educacional, afirmando que ela nos possibilita ver o que sempre vimos até então, fazendo-nos enxergar outros elementos. Obviamente não se trata aqui de uma epifania. A descoberta se dá mediante um processo de observação cuidadoso de um fenômeno social, o que remete não apenas a um acumulo de detalhes sobre uma determinada realidade. $\mathrm{O}$ que se mostra ainda mais importante no caso da Etnografia é a relevância que damos a esses detalhes, processo este que se dá em contínua reflexão com o que é encontrado em campo e também com a própria tradição teórica da disciplina antropológica. Nesse caso, não apenas a reflexão deve ser instaurada com uma reflexão mais ampla com as ciências da educação de forma geral.

Assim, com base nas observações desses autores e de muitos outros antropólogos que sempre refletiram sobre seu trabalho de campo, é possível postular, de uma maneira sintética, que a etnografia é uma forma especial de operar em que o pesquisador entra em contato com o universo dos pesquisados e compartilha seu horizonte, não para permanecer lá ou mesmo para atestar a lógica de sua visão de mundo, mas para, seguindo-os até onde 
seja possível, numa verdadeira relação de troca, comparar suas próprias teorias com as deles e assim tentar sair com um modelo novo de entendimento ou, ao menos, com uma pista nova, não prevista anteriormente.

Esse é um insight, uma forma de aproximação própria da abordagem etnográfica que produz um conhecimento diferente do obtido por intermédio da aplicação de outros métodos. Tratase de um empreendimento que supõe um determinado tipo de investimento, um trabalho paciente e contínuo ao cabo do qual e em algum momento, como mostrou Lévi-Strauss, os fragmentos se ordenam, perfazendo um significado até mesmo inesperado. (MAGNANI, 2009, p. 135)

Para além do que já foi exposto, é importante apontar que negamos os subterfúgios muitas vezes utilizados que afirmam as pesquisas como "do tipo", "de cunho", "de caráter", "de inspiração" etnográfica (OLIVEIRA A., 2013b), sem com isso haver maiores esclarecimentos metodológicos, buscando, por vezes, reduzir a Etnografia a uma técnica de coleta de dados. Nesse sentido, é preciso deixar bastante claro aqui que, no caso da pesquisa etnográfica, não se trata de dados a serem coletados, pois o que ocorre de fato é um processo de construção dos dados, que se dá na interação entre o pesquisador e o pesquisado. Assumimos, portanto, um caráter afirmativo com relação ao desenvolvimento de etnografias em Educação.

Nessa direção, também Magnani (2012), em entrevista recentemente publicada, aponta a seguinte questão:

É preciso ressaltar que a etnografia é um método, não uma mera ferramenta de pesquisa, pronta, que se pode usar de qualquer maneira. Como método, foi forjada pela antropologia ao longo da sua formação e não pode ser utilizada, sem mais, ignorando os diferentes contextos teóricos que lhe dão fundamento. Se não, ela passa de método a ferramenta, sendo empregada de maneira trivial, rasa. Isso não quer dizer que outras áreas não possam utilizar e se apropriar do nosso método de trabalho, mas com o devido cuidado; do contrário, perde consistência. A expressão "observação participante", então, virou lugar comum; qualquer ida a campo vira observação participante. Os profissionais de outras áreas precisam entender que para produzir uma etnografia, é preciso antes conhecer as boas etnografias que já foram feitas. (p. 175) 
R. Oliveira (2006) chama atenção para o fato de que o fazer etnográfico implica ver, ouvir e escrever, e que essas atitudes cognitivas são treinadas dentro da tradição da própria Antropologia. Para o autor:

[...] os atos de olhar e de ouvir são, a rigor, funções de um gênero de observação muito peculiar - isto é, peculiar à antropologia -, por meio da qual o pesquisador busca interpretar - ou compreender - a sociedade a cultura do outro "de dentro", em sua verdadeira interioridade." (p. 34)

Vale a pena ressaltar uma questão trazida por Barth (2000), ao chamar atenção para o fato de os pesquisadores darem demasiada atenção ao que os informantes falam e pouca relevância ao que eles falam entre si, quando muitas vezes residem nesses diálogos importantes elementos de compreensão da realidade analisada, mais do que nos dados obtidos por meio de entrevistas.

Essa questão toma uma especial relevância no caso de pesquisas em contextos escolares, uma vez que há a necessidade de um contínuo esforço de transformar o familiar em exótico, em estranhar uma realidade com a qual estamos profundamente familiarizados, seja por meio dos longos anos de escolarização pelos quais passamos, seja devido à proximidade com a realidade escolar mediante o universo da pesquisa. Obviamente que essa não é uma tarefa simples, e que nunca é realizada inteiramente (DAMATTA, 1978), mas que deve ser buscada pelo pesquisador ao reconhecer a necessidade de estranhar aquela realidade. Ao revisitar o tema da utilização da Etnografia na pesquisa acerca do universo da sala de aula, Sirota (1994) aponta as seguintes questões:

Os processos de investigação utilizados na sala de aula deverão então, de acordo com K. Wilcox, em seu artigo Ethnography as a methdology an its application to the study of schooling (1982), seguir os princípios seguintes: - explorar a situação tal como vivenciada e construída pelos participantes; - tornar o familiar estranho, anotando tudo que é considerado como evidente; - analisar a relação entre a situação da sala de aula e seu contexto; - não construir as hipóteses e os instrumentos de observação senão a partir do campo; - interpretar os fatos observados no quadro das teorias antropológicas. Devese assim chegar a uma descrição exaustiva que deve capturar os detalhes concretos da vida cotidiana da sala de aula, tanto ao nível das rotinas, quanto dos incidentes-chave. (p. 29) 
Não se trata de estabelecer uma "fórmula" de como aplicar a etnografia nas pesquisas em Educação, mas de reconhecer que há procedimentos recorrentes na prática etnográfica que devem ser considerados, como o processo de rotinização do trabalho de campo, que é certamente algo que ajuda substancialmente o pesquisador nessa tarefa, a leitura de outras etnografias, a revisão da literatura sobre o tema, a elaboração do seu projeto, do seu cronograma, assim como o diário de campo, que adquire certamente uma centralidade na pesquisa etnográfica. Como nos aconselha Pires (2011, p. 146):

O diário de campo é um instrumento poderoso na pesquisa antropológica. Estejam sempre com ele a postos (não necessariamente em mãos, para evitar a natural curiosidade daqueles que se sabem observados) e reservem um momento ao longo do dia para relatar os acontecimentos passados. Os diários podem ser exclusivamente descritivos, mas devem ser exaustivamente minuciosos. Mesmo que a princípio não consigamos enxergar a necessidade de mencionar detalhes, eles podem, no mínimo, fazer a diferença no futuro num processo de rememoração do trabalho de campo através da leitura do diário. A sugestão é que tudo seja anotado. Além disso, as sutilezas são essenciais para a construção de um retrato fiel da vida social, como mostra com maestria Max Gluckman no texto "Análise de uma situação social na Zululândia moderna" (1976), incluindo na análise até as suas idas ao banheiro!

Também cabe aqui uma ressalva àqueles que são neófitos no campo da Antropologia, pois, por mais que o texto etnográfico busque ser o mais fidedigno possível às impressões vivenciadas em campo, isso não implica dizer que ele se equivalha ao que o pesquisador possui em seu diário de campo, já que são escritas distintas, com processos de organização diversos. Nesse ponto, cabe a seguinte ressalva:

A redação do texto final se faz no desmembramento dessas páginas diversas, em contradição com o estabelecimento de um "verdadeiro" diário, que seria do início ao fim classificado cronologicamente. É justamente na construção de uma nova ordem, lógica e retórica ao mesmo tempo, imposta ao material coletado sem ordem, ou ainda segundo as ordens múltiplas, que se produz um texto publicável. O texto é tanto mais publicável quanto seu princípio de ordem seja mais eficaz, mais exaustivo. Idealmente, nada deveria ser subtraído. Assim a redação "final" 
da minha pesquisa conheceu, como ocorre frequentemente, duas etapas: uma tese e uma obra publicada. Na tese, para mostrar o "ateliêe" da pesquisa, um posfácio reagrupava as passagens que não se inseriam na ordem do texto. (WEBER, 2009, p. 163-164)

Se o diário é instrumento que o pesquisador se utiliza em campo também é ele que permite um afastamento do campo, possibilitando tanto uma análise do desenvolvimento da pesquisa, quanto uma autoanálise do pesquisador e de sua estada no universo de investigação, pois "Uma etnografia, enquanto texto, não deixa de ser um olhar revisto ou, se a frase soar rebarbativa aos mais sensíveis, um olhar que revê. E revê porque está em outro ângulo." (SILVA, 2009, p. 183). Esse processo contínuo de anotação e descrição na pesquisa etnográfica possui uma finalidade, pois é por meio desses dados que buscaremos relacionar fatos aparentemente singulares a outros acontecimentos, pois uma das questões fundamentais para a Etnografia é a dimensão da totalidade. Nesse ponto, cabe mais uma ressalva sobre as possíveis armadilhas na utilização da Etnografia na pesquisa educacional. Muitas vezes esta é buscada considerando-se que a pesquisa dar-se-á com um " pequeno grupo", logo a pesquisa etnográfica se faria pertinente, o que pode ser verificado especialmente no caso de pesquisas restritas a uma única classe escolar, ou a um pequeno grupo de educação não formal. Todavia, devemos ressaltar aqui que não há um automatismo entre essas questões, a etnografia não é simplesmente o "estudo dos pequenos grupos", até mesmo porque tanto há outras possibilidades metodológicas de se abordar determinadas unidades, como também há etnografias que se propõem a realizar uma descrição mais ampla, envolvendo vários grupos sociais.

Percebemos que os fatos idiossincráticos que encontramos em campo com o tempo não são tão sui generis assim, pois acontecimentos pontuais se relacionam com eventos mais amplos, com regularidades que são percebidas na escola $X$ e, também, na escola Y. Portanto, devemos considerar que:

Partir das regularidades, dos padrões e não das dissonâncias ou desencontros como condição da pesquisa supõe uma contrapartida no plano teórico: alguma ideia de totalidade como pressuposto. Não se trata, evidentemente, daquela totalidade que evoca um 
todo orgânico, funcional, sem conflitos e tampouco se trata de uma totalidade que coincide, no caso da cidade, com os seus limites político-administrativos. No entanto, renunciar a esses tipos de totalidade não significa embarcar no extremo oposto: um mergulho na fragmentação pois, se não se pode delimitar uma única ordem, isso não significa que não haja nenhuma. A questão da totalidade coloca-se, dessa maneira, em múltiplos planos e escalas. (MAGNANI, 2009, p. 137, grifo do autor)

Colocando nesses termos, a impressão que temos é que a pesquisa etnográfica é extremamente caótica; talvez seja um pouco, na medida em que não há apenas procedimentos a serem seguidos, mas uma verdadeira experiência vivenciada pelo pesquisador, que, quando transformada em texto, busca convergir o tempo da ação com o tempo da narração. Sua estada em campo implica negociações cotidianas do sentimento de pertencimento ou de exclusão, em que todos os elementos estão numa relação de "intersignificação" (ECKERT; ROCHA, 1998).

Essas questões se colocam de forma ainda mais explícita em alguns campos, como no caso das pesquisas que envolvem crianças. Corsaro (2005) aponta para os seus percalços em campo na pesquisa etnográfica com crianças. Ele reconhece a necessidade de se inserir na cultura própria desses sujeitos, e de ser aceito por eles para que a pesquisa possa se desenvolver. E isso não se dá de forma automática, mas gradual. No caso específico de pesquisas em realidades escolares, deve-se considerar também a aceitação por parte dos professores para o desenvolvimento da pesquisa, uma vez que, ao contrário de outras abordagens metodológicas - em que os procedimentos de pesquisa podem ser realizados de forma pontual, por meio da aplicação de questionários, ou realização de entrevistas -, a Etnografia pressupõe estada em campo, possibilidade de vivenciar uma dada realidade para que esta possa ser apreendida pelo texto etnográfico.

Essas tensões no processo de aceitação do pesquisador envolvem os múltiplos agentes sociais envolvidos na realidade escolar. Eugênio (2003) nos relata as vicissitudes de seu trabalho de campo em uma escola especializada para crianças cegas, apontando para as diversas posturas que encontrou entre os vários agentes envolvidos, bem como para a indefinição de seu papel naquele espaço. Segundo a pesquisadora: 
Se, entre as professoras, minha aceitação não foi imediata, deu-se o oposto com as crianças. A receptividade delas me surpreendeu. [...] A receptividade que marcou minha relação com as crianças cedeu lugar ao clima oposto em minha relação com as mães. A desconfiança, aqui, não foi passageira, como a das tias comigo. Em meu contato com as mães, se manteve sempre algum grau de tensão - em parte, talvez, por serem todas elas "videntes" e, portanto, perceberem minha postura de "observadora em tempo integral", de caderno em punho, fosse qual fosse a atividade paralela que me incumbissem. (p. 216-217)

Nesta breve descrição, podemos perceber que a peculiaridade do método etnográfico leva à existência de desafios próprios. Há uma necessidade que se impõe ao pesquisador de explicitar aos agentes envolvidos não apenas os objetivos de sua pesquisa, mas os fundamentos do seu método. Mostra-se interessante, portanto, que os agentes sociais da realidade pesquisada - alunos, professores, pais de alunos, gestores - sejam esclarecidos sobre a necessidade da permanência contínua observador do pesquisador em campo, o que também é relevante para outros métodos de pesquisa. Todavia, no caso da Etnografia, considerando o contínuo processo de contato e de observação de uma dada realidade, isso se coloca de forma mais evidente.

No caso específico das etnografias desenvolvidas em escolas, percebemos que muitos pesquisadores indicam uma "confusão de identidades", sendo o seu lugar de difícil classificação, muitas vezes interpretados ali como mais um professor. Em alguns casos, chegam mesmo a assumir essa identidade, como nos aponta a pesquisa de Fritzen (2012), o que obviamente deve ser problematizado ao longo da pesquisa.

Também cabe aqui ressaltar que o método etnográfico é "perigoso", pois pressupõe, no processo contínuo com o outro, um exercício de alteridade, por meio do qual não apenas esse outro é pensado, mas também nós mesmos. Isso se dá na imersão da cultura do outro, na necessidade de compreender "de dentro" uma dada realidade. Em nosso entendimento, isso se mostra ainda mais complexo no caso das pesquisas em Educação, justamente pela familiaridade que possuímos a priori com esse universo. Acerca de tais questões, é válido ressaltar que: 
Sublinho apenas que a posição de Geertz significa que os antropólogos são um tipo de cientista social para quem a socialidade não é apenas o objeto ou o objetivo da investigação, mas o principal, se não o único, meio de pesquisa. O cerne da questão é a disposição para viver uma experiência pessoal junto a um grupo humano com o fim de transformar essa experiência pessoal em tema de pesquisa que assume a forma de um texto etnográfico. Nesse sentido, a característica fundamental da antropologia seria o estudo das experiências humanas a partir de uma experiência pessoal. E é por isso, penso, que alteridade seja a noção ou a questão central da disciplina, o princípio que orienta e inflete, mas também limita, a nossa prática. Parte da nossa tarefa consiste em descobrir por que aquilo que as pessoas que estudamos fazem e dizem parece-lhes, eu não diria evidente, mas coerente, conveniente, razoável. Mas a outra parte consiste em estar sempre se interrogando sobre até que ponto somos capazes de seguir o que elas dizem e fazem, até onde somos capazes de suportar a palavra nativa, as práticas e os saberes daqueles com quem escolhemos viver por um tempo. E, por via de consequência, até onde somos capazes de promover nossa própria transformação a partir dessas experiências. (GOLDMAN, 2006, p. 167)

Portanto, instaura-se uma contínua tensão que compõe, em verdade, os fundamentos epistemológicos da própria etnografia, pois ela é construída nessa problematização da relação do eu com o outro; em última instância, da minha cultura com a cultura que me proponho a investigar. Mesmo no caso de pesquisas desenvolvidas na mesma sociedade do pesquisador, como ocorre na maior parte das pesquisas educacionais, seria uma ilusão acreditar que essa questão não se coloca. Devemos reconhecer o caráter distributivo da cultura (BARTH, 2000), de modo que os diferentes agentes vivenciam e interpretam a cultura que partilham de diversas formas, relacionando-se tanto a suas experiências sociais quanto individuais, o que deve ser objeto de reflexão sistemática por parte do pesquisador.

\section{Considerações finais}

Voltar-se para a escola implica necessariamente reconhecer a diversidade existente nesse espaço, a multiplicidade de identidades acionadas e os vários modos que isso ocorre. Em nosso entendimento, 
isso pode ser realizado de forma bastante contundente por meio da Etnografia, ainda que nesse ponto se deva perceber tanto os ganhos significativos que ela traz, quanto os cuidados que devem ser tomados, dando especial atenção para a indissociabilidade entre teoria e método.

Não procuramos ao longo deste trabalho produzir um mapa de como proceder na pesquisa etnográfica. Em verdade, acreditamos na impossibilidade de se "ensinar" a fazer Etnografia. O máximo que se pode fazer é indicar algumas questões em termos de procedimentos metodológicos que podem colaborar para a construção do aparato metodológico de uma dada pesquisa. Contudo, a experiência etnográfica é singular, remetendo a elementos como a biografia do pesquisador, sua relação com o objeto de investigação e as intempéries encontradas em campo.

Ressalta-se que há uma íntima relação entre a Etnografia e a Antropologia, de modo que não se pode propor uma pesquisa etnográfica sem se debruçar sobre o desenvolvimento da etnografia na própria história da ciência antropológica, buscando, portanto, conhecer profundamente os avanços, embates e desdobramentos desse método no terreno no qual ele foi forjado. Muitas confusões na apropriação da Etnografia, sobretudo por pesquisadores da Educação, originamse em razão da ausência desse exercício, pois, em muitos casos, os pesquisadores que afirmam se utilizar de tal metodologia desconhecem o vasto debate nesse campo.

Por fim, cabe ressaltar que, assim como qualquer outra metodologia, a Etnografia apresenta limites, que nesse caso se confundem com suas próprias potencialidades, pois ambos residem na forma como os dados são produzidos na relação intersubjetiva que se estabelece entre o pesquisador e o pesquisado, que se constrói no encontro etnográfico. Ao contrário de outras metodologias que nos possibilitam tornar a experiência social um objeto de reflexão, a Etnografia transforma tal experiência em meio para a delimitação e investigação do objeto, o que se mostra bastante complexo quando envolve a realidade educacional. 


\section{Referências}

ANDRÉ, M. Etnografia da prática escolar. Campinas: Papirus: 1995.

ANDRÉ, M. Tendências atuais da pesquisa na escola. Cadernos do CEDES, Campinas, v. 23, n. 43, p. 46-57, 1997.

ALVES-MAZOTTI, A. J. Relevância e aplicabilidade da pesquisa em educação. Cad. Pesqui., São Paulo, n. 113, p. 39-50, 2001.

BARTH, F. O guru, o iniciador e outras variações antropológicas. Rio de Janeiro: Contra Capa Livraria, 2000.

CAMPOS, M. M. Para que serve a pesquisa em educação? Cad. Pesqui., v. 39, n. 136, p. 269-283, 2009.

CHIZZOTTI, A. Pesquisa qualitativa em Ciências Humanas e Sociais. Revista Portuguesa de Educação, Portugal, v. 16, n. 1, p. 12-20, 2003.

COULON, A. Etnometodologia e Educação. Petrópolis, RJ: Vozes, 1995.

CORSARO, W. A. Entrada no campo, aceitação e natureza da participação nos estudos etnográficos com crianças pequenas. Educ. Soc., Campinas, v. 26, n. 91, p. 443-464, 2005.

DAMATTA, R. O ofício do etnólogo, ou como ter 'Anthropological Blues'. In: NUNES, E. de O. (Org.). A aventura sociológica: objetividade, paixão, improviso e método na pesquisa social. Rio de Janeiro: Zahar Editores, 1978. p. 23-35.

DAUSTER, T. Um saber de fronteira - entre a antropologia e a educação. In: DAUSTER, T. (Org.). Antropologia e educação: um saber de fronteira. Rio de Janeiro: Forma \& Ação, 2007. p. 13-35. 
ECKERT, C.; ROCHA, A. L. C. da. A interioridade da experiência temporal do antropólogo como condição da produção etnográfica. Revista de Antropologia, São Paulo, v. 41, n. 2, p. 107-135, 1998.

ECKERT, C.; ROCHA, A. L. C. da. Etnografia de rua: estudo de antropologia urbana. Iluminuras, Porto Alegre, v. 3, n. 7, p. 1-22, 2003.

EUGÊNIO, F. De como olhar onde não se vê: ser antropóloga e ser tia em uma escola especializada para crianças cegas. In: VELHO, G.; KUSCHNIR, K. (Orgs.). Pesquisas urbanas: desafios do trabalho antroplógico. Rio de Janeiro: Jorge Zahar Ed., 2003. p. 208-220.

FRITZEN, M. P. O olhar da etnografia no fazer pesquisa qualitativa: algumas reflexões teórico-metodológicas. In: FRITZEN, M. P.; LUCENA, M. I. (Orgs.). O olhar da etnografia em contextos educacionais: interpretando práticas de linguagem. Blumenau: Edifurb, 2012. p. 55-71.

GARCIA, T. M. F. B. Origens e questões da etnografia educacional no Brasil: um balanço de teses e dissertações (1981-1998). 2001. 308 f. Tese (Doutorado em Educação) - Faculdade de Educação, Universidade de São Paulo, São Paulo, 2001.

GATTI, B. A. Implicações e perspectivas da pesquisa educacional no Brasil cotemporâneo. Cad. Pesqui., São Paulo, n. 113, p. 65-81, jul. 2001.

GATTI, B.; ANDRÉ, M. A relevância dos métodos de pesquisa qualitativa em Educação no Brasil. In: WELLER, V.; PFAFF, N. (Orgs.). Metodologias da Pesquisa Qualitativa em Educação: teoria e prática. Petrópolis, RJ: Vozes, 2011. p. 29-38.

GEERTZ, C. A interpretação das culturas. Rio de Janeiro: LTC, 1989.

GEERTZ, C. Obras e vidas: o antropólogo como autor. Rio de Janeiro: Editora da UFRJ, 2005. 
GOLDMAN, M. Alteridade e experiência: Antropologia e Teoria Etnográfica. Etnográfica, Portugal, v. 10, n. 1, p. 161-173, 2006.

GUSMÃO, N. M. Antropologia e Educação: história e trajetos. In: GROSSI, M. P.; TASSINARI, A.; RIAL, C. (Org.). Ensino de Antropologia no Brasil: formação, práticas disciplinares e alémfronteiras. Blumenau: Nova Letra, 2006. p. 299-331.

LIMA, P. G. Tendências paradigmáticas na pesquisa educacional. 2001. 301 f. Dissertação (Mestrado em Educação) - Faculdade de Educação, Universidade Estadual de Campinas, Campinas, 2001.

MAGNANI, J. G. C. Etnografia como prática e experiência. Horizontes Antropológicos, Porto Alegre, v. 32, p. 129-156, 2009.

MAGNANI, J. G. C.; AQUINO, J. D. A etnografia não é um método, não uma mera ferramenta de pesquisa..., que se pode usar de qualquer maneira. Revista de Ciências Sociais, Fortaleza, v. 43, p. 252266, 2012.

MALINOWSKI, B. Os argonautas do Pacífico Ocidental. São Paulo: Abril Cultural, 1976.

MARTINS, H. H. T. S. Metodologia qualitativa de pesquisa. Educação e Pesquisa, São Paulo, v. 30, p. 289-300, 2004.

OLIVEIRA, A. Antropologia e antropólogos, Educação e educadores: o lugar do ensino de Antropologia na formação docente. Percursos, Maringá, v. 13, p. 120-132, 2012.

OLIVEIRA , A. O lugar da antropologia na formação docente: um olhar a partir das escolas normais. Pro-Posições, Campinas, v. 24, n. 2, p. 27-40, 2013a. 
OLIVEIRA, A. Por que etnografia no sentido estrito e não estudos do tipo etnográfico em educação? Revista FAEEBA, Salvador, v. 22, n. 40, p. 69-82, 2013b.

OLIVEIRA, R. C. de. O trabalho do antropólogo. São Paulo: Editora UNESP, 2006.

PEIRANO, M. A favor da Etnografia. Rio de Janeiro: Relume Dumara, 1995.

PIRES, F. F. Roteiro sentimental para o trabalho de campo. Cadernos de Campo, São Paulo, n. 20, p. 143-148, 2011.

ROCHA, G.; TOSTA, S. P. Antropologia \& Educação. Belo Horizonte: Autêntica, 2009.

SILVA, H. R. S. A situação etnográfica: andar e ver. Horizontes Antropológicos, Porto Alegre, v. 32, p. 171-188, 2009.

SIROTA, R. A escola primária no cotidiano. Porto Alegre: Artes Médicas, 1994.

TOSTA, S. P.; MOREIRA, H.; BUENICONTRO, R. Os usos da etnografia na pesquisa educacional. In: REUNIÃO BRASILEIRA DE ANTROPOLOGIA: DILEMAS DA (DES)IGUALDADE NA DIVERSIDADE, 26. 2008. Porto Seguro. Anais... Porto Seguro, 2008. p. $1-14$.

VALENTE, A. L. E. F.. Usos e abusos da Antropologia na pesquisa educacional. Pro-Posições, Campinas, v. 7, n. 20, p. 54-64, 1996.

WEBER, F. A entrevista, a pesquisa e o íntimo, ou por que censurar seu diário de campo?. Horiz. Antropol., Porto Alegre, v. 15, n. 32, p. 157-170, 2009.

Recebido: 05/07/2013

Aprovado: 25/11/2013 